\title{
FINITE ELEMENT ANALYSIS OF LAMINATED COMPOSITE PLATES USING HIGH ORDER SHEAR DEFORMATION THEORY
}

\author{
NGo NHU KHOA \\ Thainguyen University \\ TRAN ICH THINH \\ Hanoi University of Technology
}

\begin{abstract}
A rectangular non-conforming element based on Reddy's higher-order shear deformation plate theory is developed. Although the plate theory is quite attractive but it could not be exploited as expected in finite-element analysis. This is due to the difficulties associated with satisfaction of inter-elemental continuity requirement and satisfy zero shear stress boundary conditions of the plate theory. In this paper, the proposed element is developed where Reddy's plate theory is successfully implemented. It has four nodes and each node contains 7 degrees of freedom. The performance of the element is tested with different numerical examples, which show its precision and range of applicability.
\end{abstract}

\section{INTRODUCTION}

The use of composite materials in structural components are increasing due to their attractive properties such as high strength-to-weight ratio, ability to tailor the structural properties, etc. Plate structures find numerous applications in the aerospace, military and automotive industries. The problem of shear deformation has got a good amount of attention after the popularity of fiber reinforced laminated composites, which is now one of the major areas of research in recent times. Actually, the role of transverse shear is very important in composites, as the material is weak in shear due to its low shear modulus compared to extensional rigidity. In this context a number of plate theories have been developed where the major emphasis is to model the shear deformation in a refined manner. Amongst these plate theories (higher-order shear deformation theories - HSDT), only a representative selection is made in reference [2-9].

In single layer displacement-based theories, the plate theory proposed by Reddy [7] is most simple, elegant and useful in the context of present problem. It allows parabolic variation of transverse shear stress along the plate thickness and satisfies zero shear stress boundary conditions at the top and bottom of the plate. This has helped to eliminate the necessity of any arbitrary shear correction factor like that, which is required in FSDT. Moreover Reddy's plate theory [7] does not involve any unknown, which does not have any physical meaning like that found in some plate theories (e.g. [10,11]). The plate theory [7] has all positive features except one drawback, which is found in a situation when finite element is applied to this plate model. The problem is concerned with the continuity requirement of $w$ at the common edges between two elements. It requires $\mathrm{C}^{1}$ continuity of $w$ as the strain terms contain second-order derivatives of $w$. This problem is identical to 
that experienced in the development of thin-plate elements as mentioned earlier. This has rather put the main constrain in exploiting such an elegant plate theory in finite element analysis as expected [4].

In this context, A. H. Sheikh and A. Chakrabarti [4] has developed a triangular element. The basic element [4] has six nodes (three corner nodes and three mid-side nodes) where each node contains $u ; v ; w ; \theta_{x}, \theta_{y}, \gamma_{x}$ and $\gamma_{y}$ as the degrees of freedom. In this element, the field variables are $u ; v ; w, \gamma_{x}$ and $\gamma_{y}$ where all the field variables except $w$ are approximated by a complete quadratic polynomial having six unknowns. The transverse displacement $w$ is approximated by a truncated quintic polynomial having 18 unknowns. The element is quite complicated, unfortunately, they [4] didn't show the Hermite interpolation funtions.

Keeping all the aspects in view, an attempt has been made to develop a rectangular element based on higher-order shear deformation theory of Reddy [7]. It has four corner nodes, where each node contains $u ; v ; w ; \theta_{x} ; \theta_{y} ; \gamma_{x}$ and $\gamma_{y}$ as the degrees of freedom. In this element, the field variables are $u ; v ; \gamma_{x}$ and $\gamma_{y}$ where all the field variables are approximated by a complete quadratic polynomial having four unknowns. The transverse displacement $w$ and $\theta_{x}, \theta_{y}$ are approximated by a truncated quintic polynomial having 12 unknowns. With all these efforts, it is found that the element does not satisfy the continuity requirement of normal slope. Thus, the proposed element is non-conforming but the performance of the element is excellent in a wide range of problems, which include different boundary condition, plate geometry, aspect ratio, stacking sequence, load distribution and so on.

\section{ELASTICITY EQUATIONS}

According to Reddy plate theory [7], the displacement components of a point at a distance of $\mathrm{z}$ from the reference plane may be expressed in terms field variables (displacement parameters at the reference plane) as:

$$
\begin{aligned}
& u(x, y, z)=u^{0}(x, y)-z\left[\left(\frac{\partial w}{\partial x}+\gamma_{x}\right)-\frac{4}{3}\left(\frac{z}{h}\right)^{2} \gamma_{x}\right] \\
& v(x, y, z)=v^{0}(x, y)-z\left[\left(\frac{\partial w}{\partial y}+\gamma_{y}\right)-\frac{4}{3}\left(\frac{z}{h}\right)^{2} \gamma_{y}\right] \\
& w(x, y, z)=w^{0}(x, y) .
\end{aligned}
$$

According to Reddy's plate theory [7], the strain vector $\{\varepsilon\}$ may be expressed as:

$$
\{\varepsilon\}=\left\{\begin{array}{l}
\varepsilon_{x} \\
\varepsilon_{y} \\
\gamma_{x y} \\
\gamma_{y z} \\
\gamma_{x z}
\end{array}\right\}=\left\{\begin{array}{l}
\varepsilon_{x}^{0} \\
\varepsilon_{y}^{0} \\
\gamma_{x y}^{0} \\
\gamma_{y z}^{0} \\
\gamma_{x z}^{0}
\end{array}\right\}+z\left\{\begin{array}{l}
k_{x} \\
k_{y} \\
k_{x y} \\
0 \\
0
\end{array}\right\}+z^{2}\left\{\begin{array}{l}
0 \\
0 \\
0 \\
\chi_{y z} \\
\chi_{x z}
\end{array}\right\}+z^{3}\left\{\begin{array}{l}
\eta_{x} \\
\eta_{y} \\
\eta_{x y} \\
0 \\
0
\end{array}\right\},
$$

where

$$
\left\{\begin{array}{l}
\varepsilon_{x}^{0} \\
\varepsilon_{y}^{0} \\
\gamma_{x y}^{0}
\end{array}\right\}=\left\{\begin{array}{l}
u_{\prime_{x}}^{0} \\
v_{x_{y}}^{0} \\
u_{x_{y}}^{0}+v_{x_{x}}^{0}
\end{array}\right\} ; \quad\left\{\begin{array}{l}
k_{x} \\
k_{y} \\
k_{x y}
\end{array}\right\}=-\left\{\begin{array}{l}
w_{x x}+\gamma_{x^{\prime} x} \\
w_{y y}+\gamma_{y^{\prime} y} \\
2 w_{x y}+\gamma_{x^{\prime} y}+\gamma_{y^{\prime} x}
\end{array}\right\} ;
$$




$$
\begin{aligned}
& \left\{\begin{array}{l}
\eta_{x} \\
\eta_{y} \\
\eta_{x y}
\end{array}\right\}=\frac{4}{3 h^{2}}\left\{\begin{array}{l}
\gamma_{x^{\prime} x} \\
\gamma_{y^{\prime} y} \\
\gamma_{x^{\prime} y}+\gamma_{y^{\prime} x}
\end{array}\right\} ; \\
& \left\{\begin{array}{c}
\gamma_{y z}^{0} \\
\gamma_{x z}^{0}
\end{array}\right\}=-\left\{\begin{array}{c}
\gamma_{y} \\
\gamma_{x}
\end{array}\right\} ; \quad\left\{\begin{array}{l}
\chi_{y z} \\
\chi_{x z}
\end{array}\right\}=\frac{4}{h^{2}}\left\{\begin{array}{l}
\gamma_{y} \\
\gamma_{x}
\end{array}\right\} .
\end{aligned}
$$

The above equations show that the transverse shear strains: $\gamma_{x z}$ and $\gamma_{y z}$ have parabolic variation along $z$ and they are zero at the top and bottom $(z= \pm h / 2)$ of the plate as mentioned earlier. The linear constitutive equation of the $k^{\text {th }}$ layer is given by:

$$
\left[\begin{array}{l}
\sigma_{x} \\
\sigma_{y} \\
\sigma_{x y} \\
\sigma_{y z} \\
\sigma_{x z}
\end{array}\right]_{k}=\left[\begin{array}{lllll}
C_{11}^{\prime} & C_{12}^{\prime} & C_{16}^{\prime} & 0 & 0 \\
C_{12}^{\prime} & C_{22}^{\prime} & C_{26}^{\prime} & 0 & 0 \\
C_{16}^{\prime} & C_{26}^{\prime} & C_{66}^{\prime} & 0 & 0 \\
0 & 0 & 0 & C_{44}^{\prime} & C_{45}^{\prime} \\
0 & 0 & 0 & C_{45}^{\prime \prime} & C_{55}^{\prime}
\end{array}\right]_{k}\left[\begin{array}{c}
\varepsilon_{x} \\
\varepsilon_{y} \\
\gamma_{x y} \\
\gamma_{y z} \\
\gamma_{x z}
\end{array}\right]_{k}
$$

The rigidity matrix $\left[C_{i j}^{\prime}\right]$ in the above equations can be evaluated with the material properties $\left(E_{1}, E_{2}, E_{3}, \nu_{12}, \nu_{13}, \nu_{23}, G_{12}, G_{13}\right.$ and $\left.G_{23}\right)$ and fibre orientation of the lamina. The details are not presented, as it is available in any standard text on mechanics of laminated composites [1].

By integrating the stresses through the plate thickness, we obtained the generalized force-strain relation:

$$
\left[\begin{array}{l}
N \\
M \\
P \\
Q \\
W
\end{array}\right]=\left[\begin{array}{lllll}
A & B & E & 0 & 0 \\
B & D & F & 0 & 0 \\
E & F & H & 0 & 0 \\
0 & 0 & 0 & A^{\prime} & D^{\prime} \\
0 & 0 & 0 & D^{\prime} & F^{\prime}
\end{array}\right]\left[\begin{array}{l}
\varepsilon^{0} \\
k \\
\eta \\
\gamma^{0} \\
\chi
\end{array}\right]
$$

where different quantities of the rigidity matrix in Eq. (2.5) can be derived as follows:

$$
\begin{aligned}
& \left(A_{i j} B_{i j} D_{i j} E_{i j} F_{i j} H_{i j}\right)=\sum_{k=1}^{n} \int_{h_{k-1}}^{h_{k}}\left(C_{i j}^{\prime}\right)_{k}\left(1 z z^{2} z^{3} z^{4} z^{6}\right) d z, i, j=1,2,6 . \\
& \left(A_{i j}^{\prime} D_{i j}^{\prime} F_{i j}^{\prime}\right)=\sum_{k=1}^{n} \int_{h_{k-1}}^{h_{k}}\left(C_{i j}^{\prime} t\right)_{k}\left(1 z^{2} z^{4}\right) d z, \quad i, j=4,5 .
\end{aligned}
$$

\section{FINITE ELEMENT FORMULATION}

The formulation is based on the assumptions followed in Reddy's plate theory [7]. The middle plane of the plate is taken as the reference plane.

According to (2.2), there are 7 displacement components on a node. We have a nodal displacement vector:

$$
d_{i}=\left\{\begin{array}{llll}
u_{i}^{0} & v_{i}^{0} & w_{i}^{0} & \left(\frac{\partial w}{\partial x}\right)_{i}
\end{array}\left(\frac{\partial w}{\partial y}\right)_{i}\left(\gamma_{y}\right)_{i}\left(\gamma_{x}\right)_{i}\right\}^{T},
$$


7 components are 7 freedoms of a node, respectively:

$$
d_{i}=\left\{q_{i}, q_{i+1}, q_{i+2}, q_{i+3}, q_{i+4}, q_{i+5}, q_{i+6}\right\}^{T} .
$$

Therefore, the element nodal displacement vector are presented by:

$$
a=\left\{\begin{array}{llll}
d_{1}^{T} & d_{2}^{T} \cdots & d_{i}^{T} & d_{n}^{T}
\end{array}\right\}^{T}
$$

and the displacement vector of element may be expressed as:

$$
d=\left\{\begin{array}{lllllll}
u^{0} & v^{0} & w^{0} & \theta_{x} & \theta_{y} & \gamma_{x} & \gamma_{y}
\end{array}\right\}^{T} .
$$

According to the discussions made in the previous section, the field variables i.e., the independent displacement components at the reference plane may be expressed as follows:

$$
\begin{aligned}
& {\left[\begin{array}{llll}
u^{0} & v^{0} & \gamma_{x} & \gamma_{y}
\end{array}\right]^{T}=\left[\begin{array}{ll}
\sum_{i=1}^{N} N_{i} u_{i}^{0} & \sum_{i=1}^{N} N_{i} v_{i}^{0} \sum_{i=1}^{N} N_{i} \gamma_{x i} \sum_{i=1}^{N} N_{i} \gamma_{y i}
\end{array}\right]^{\dot{T}}} \\
& w=H_{1} w_{1}^{0}+H_{2}\left(\frac{\partial w}{\partial x}\right)_{1}+H_{3}\left(\frac{\partial w}{\partial y}\right)_{1}+\ldots+H_{3 N-2} w_{N}^{0}+H_{3 N-1}\left(\frac{\partial w}{\partial x}\right)_{N}+H_{3 N}\left(\frac{\partial w}{\partial y}\right)_{N} \\
& \theta_{x}=\frac{\partial w}{\partial x}+\gamma_{x}=\frac{\partial}{\partial x} \sum_{i=1}^{N}\left(H_{3 i-2} \bar{w}_{i}^{0}+H_{3 i-1}\left(\frac{\partial w}{\partial x}\right)_{i}+H_{3 i}\left(\frac{\partial w}{\partial y}\right)_{i}\right)+\sum_{i=1}^{N} N_{i} \gamma_{x i} \\
& \theta_{y}=\frac{\partial w}{\partial y}+\gamma_{y}=\frac{\partial}{\partial y} \sum_{i=1}^{N}\left(H_{3 i-2} w_{i}^{0}+H_{3 i-1}\left(\frac{\partial w}{\partial x}\right)_{i}+H_{3 i}\left(\frac{\partial w}{\partial y}\right)_{i}\right)+\sum_{i=1}^{N} N_{i} \gamma_{y i}
\end{aligned}
$$

where $N$ is the number of nodes of element, $N_{i}$ are the Lagrange interpolations functions and $H_{i}$ are the Hermite interpolation functions.

The displacement vector is interpolated through element nodal displacement vector as:

$$
d=B a
$$

where $B$ is interpolation matrix and is defined by:

$$
B=\left[\begin{array}{lllllllll}
N_{1} & 0 & 0 & 0 & 0 & 0 & 0 & N_{2} & \cdots \\
0 & N_{1} & 0 & 0 & 0 & 0 & 0 & 0 & \cdots \\
0 & 0 & H_{1} & H_{2} & H_{3} & 0 & 0 & 0 & \cdots \\
0 & 0 & \frac{\partial}{\partial x} H_{1} & \frac{\partial}{\partial x} H_{2} & \frac{\partial}{\partial x} H_{3} & 0 & N_{1} & 0 & \cdots \\
0 & 0 & \frac{\partial}{\partial y} H_{1} & \frac{\partial}{\partial y} H_{2} & \frac{\partial}{\partial y} H_{3} & N_{1} & 0 & 0 & \cdots \\
0 & 0 & 0 & 0 & 0 & 0 & N_{1} & 0 & \cdots \\
0 & 0 & 0 & 0 & 0 & N_{1} & 0 & 0 & \cdots
\end{array}\right.
$$




$\left.\begin{array}{lllllll}N_{n} & 0 & 0 & 0 & 0 & 0 & 0 \\ 0 & N_{n} & 0 & 0 & 0 & 0 & 0 \\ 0 & 0 & H_{3 N-2} & H_{3 N-1} & H_{3 N} & 0 & 0 \\ 0 & 0 & \frac{\partial}{\partial x} H_{3 N-2} & \frac{\partial}{\partial x} H_{3 N-1} & \frac{\partial}{\partial x} H_{3 N} & 0 & N_{N} \\ 0 & 0 & \frac{\partial}{\partial y} H_{3 N-2} & \frac{\partial}{\partial y} H_{3 N-1} & \frac{\partial}{\partial y} H_{3 N} & N_{N} & 0 \\ 0 & 0 & 0 & 0 & 0 & 0 & N_{N} \\ 0 & 0 & 0 & 0 & 0 & N_{N} & 0\end{array}\right]$

Now the field variables (2.3) may be substituted in Eqs. (3.2,3.3) and (3.8) to express the strain vector $\{\varepsilon\}$ in terms of interpolation through element nodal displacement vector as:

$$
\begin{gathered}
\left\{\varepsilon^{0}\right\}=L_{1} d=L_{1} B a=B_{1} a ;\{\kappa\}=L_{2} d=L_{2} B a=B_{2} a ;\{\eta\}=L_{3} d=L_{3} B a=B_{3} a ; \\
\left\{\gamma^{0}\right\}=L_{1}^{\prime} d=L_{1}^{\prime} B a=B_{1}^{\prime} a ; \quad\{\chi\}=L_{2}^{\prime} d=L_{2}^{\prime} B a=B_{2}^{\prime} a,
\end{gathered}
$$

where $L^{\prime}$ and $L$ are the operator matrices and can be presented by:

$$
L_{1}^{\prime}=-\left[\begin{array}{ccccccc}
0 & 0 & 0 & 0 & 0 & 1 & 0 \\
0 & 0 & 0 & 0 & 0 & 0 & 1
\end{array}\right] ; \quad L_{2}^{\prime}=\frac{4}{h^{2}}\left[\begin{array}{ccccccc}
0 & 0 & 0 & 0 & 0 & 1 & 0 \\
0 & 0 & 0 & 0 & 0 & 0 & 1
\end{array}\right]
$$

and

$$
\begin{gathered}
L_{1}=\left[\begin{array}{ccccccc}
\frac{\partial}{\partial x} & 0 & 0 & 0 & 0 & 0 & 0 \\
0 & \frac{\partial}{\partial y} & 0 & 0 & 0 & 0 & 0 \\
\frac{\partial}{\partial y} & \frac{\partial}{\partial x} & 0 & 0 & 0 & 0 & 0
\end{array}\right] ; \quad L_{2}=-\left[\begin{array}{ccccccc}
0 & 0 & 0 & \frac{\partial}{\partial x} & 0 & 0 & 0 \\
0 & 0 & 0 & 0 & \frac{\partial}{\partial y} & 0 & 0 \\
0 & 0 & 0 & \frac{\partial}{\partial y} & \frac{\partial}{\partial x} & 0 & 0
\end{array}\right] ; \\
L_{3}=\frac{4}{3 h^{2}}\left[\begin{array}{ccccccc}
0 & 0 & 0 & 0 & 0 & 0 & \frac{\partial}{\partial x} \\
0 & 0 & 0 & 0 & 0 & \frac{\partial}{\partial y} & 0 \\
0 & 0 & 0 & 0 & 0 & \frac{\partial}{\partial x} & \frac{\partial}{\partial y}
\end{array}\right]
\end{gathered}
$$

Similar to strain vector $\{\varepsilon\}$, the transverse displacement $w$ may be expressed in terms of nodal displacement vector. $\{a\}$, with the help of Eqs. (3.1), (3.2) and (3.5) as

$$
w(x, y)=B_{p} a=\{a\}^{T}\left[\begin{array}{lllllllllll}
0 & 0 & H_{1} H_{2} H_{3} & 0 & 0 & \cdots & 0 & 0 & H_{3 * N-2} H_{3 * N-1} H_{3 * N}{ }^{\prime} 0 & 0
\end{array}\right]^{T} .
$$

The present element may have any rectangular shape. This is mapped in a different plane $(\xi-\eta)$, which gives a rectangular shape. The relationship between these two axes system is as follows:

$$
\xi=\frac{2\left(x-x_{C}\right)}{a} ; \eta=\frac{2\left(y-y_{C}\right)}{b},
$$

where $a$ and $b$ are the sides of the rectangular element; $\left(x_{C}, y_{C}\right)$ are the global coordinates of the center of element. 
The interpolation functions of four-node rectangular element are determined by:

$$
\begin{array}{ll}
H_{1}=\frac{1}{8}(1-\xi)(1-\eta)\left(2-\xi-\eta-\xi^{2}-\eta^{2}\right) ; & H_{2}=\frac{1}{8}(1-\xi)(1-\eta)\left(1-\xi^{2}\right) ; \\
H_{3}=\frac{1}{8}(1-\xi)(1-\eta)\left(1-\eta^{2}\right) & H_{4}=\frac{1}{8}(1+\xi)(1-\eta)\left(2+\xi-\eta-\xi^{2}-\eta^{2}\right) ; \\
H_{5}=-\frac{1}{8}(1+\xi)(1-\eta)\left(1-\xi^{2}\right) ; & H_{6}=\frac{1}{8}(1+\xi)(1-\eta)\left(1-\eta^{2}\right) \\
H_{7}=\frac{1}{8}(1+\xi)(1+\eta)\left(2+\xi+\eta-\xi^{2}-\eta^{2}\right) ; & H_{8}=-\frac{1}{8}(1+\xi)(1+\eta)\left(1-\xi^{2}\right) ; \\
H_{9}=-\frac{1}{8}(1+\xi)(1+\eta)\left(1-\eta^{2}\right) & H_{10}=\frac{1}{8}(1-\xi)(1+\eta)\left(2-\xi+\eta-\xi^{2}-\eta^{2}\right) \\
H_{11}=\frac{1}{8}(1-\xi)(1+\eta)\left(1-\xi^{2}\right) ; & H_{12}=-\frac{1}{8}(1-\xi)(1+\eta)\left(1-\eta^{2}\right) \\
N_{i}=\frac{1}{4}\left(1+\xi \xi_{i}\right)\left(1+\eta \eta_{i}\right), & (i=1,2,3,4)
\end{array}
$$

Finally, using the finite element analysis to analyze the static behavior of the plate, the global stiffness matrix, $\{\boldsymbol{K}\}$, and the global force vector, $\{\boldsymbol{F}\}$, are needed and the equilibrium equations of them can be determined through the element stiffness matrix, $\left[K_{e}\right]$, and the nodal load vector, $\{P\}$. Where $\left[K_{e}\right]$ and $\{P\}$ are presented in compact form as the following:

$$
\left[K_{e}\right]=\int_{S_{e}}\left[\begin{array}{l}
B_{1}^{T} A B_{1}+B_{1}^{T} B B_{2}+B_{1}^{T} E B_{3}+B_{2}^{T} B B_{1}+B_{2}^{T} D B_{2}+B_{2}^{T} F B_{3}+B_{3}^{T} E B_{1}+ \\
+B_{3}^{T} F B_{2}+B_{3}^{T} H B_{3}+B_{1}^{\prime T} A^{\prime} B_{1}^{\prime}+B_{1}^{\prime T} D^{\prime} B_{2}^{\prime}+B_{2}^{\prime T} D^{\prime} B_{1}^{\prime}+B_{2}^{\prime T} F^{\prime} B_{2}^{\prime}
\end{array}\right] d S
$$

and:

$$
\iint_{S_{e}} p(x, y) w(x, y) d S=a^{T} \iint_{S_{e}}\left[B_{p}\right]^{T}\{p(x, y)\} d S=\{a\}^{T}\{P\} .
$$

The integrations in the above equations are performed numerically following Gauss quadrature technique [9].

\section{NUMERICAL RESULTS}

Numerical examples of composite plates having different features are solved by the proposed element and the results obtained are presented with the published results for necessary comparison.

Example 1. The problem of a three ply $\left(0^{0} / 90^{0} / 0^{0}\right)$ square laminate; the material properties of each ply is assumed as: $E_{1}=175 \mathrm{GPa} ; E_{2}=E_{3}=7 \mathrm{GPa} ; G_{12}=G_{13}=$ $3.5 \mathrm{GPa} ; G_{23}=1.4 \mathrm{GPa} ; \nu_{12}=\nu_{13}=0.25 ; \nu_{23}=0.01$; simply supported at all the edges and subjected to uniformly distributed load, is studied for different thickness ratios $(h / a)$ ranging from 0.1 to 0.01 . The following nondimensionalized quantities at specific points are presented in Tables.

$$
\begin{array}{ll}
\bar{w}=100 w_{0}\left(\frac{a}{2}, \frac{b}{2}\right)\left(\frac{E_{2} h^{3}}{q a^{4}}\right) ; & \bar{\sigma}_{x x}=\sigma_{x x}\left(\frac{a}{2}, \frac{b}{2}, \frac{h}{2}\right)\left(\frac{h^{2}}{|q| b^{2}}\right) ; \\
\bar{\sigma}_{y y}=\sigma_{y y}\left(\frac{a}{2}, \frac{b}{2}, \frac{h}{6}\right)\left(\frac{h^{2}}{|q| b^{2}}\right) ; & \bar{\sigma}_{x y}=\sigma_{x y}\left(0,0, \frac{h}{2}\right)\left(\frac{h^{2}}{q b^{2}}\right) ; \\
\bar{\sigma}_{y z}=\sigma_{y z}\left(\frac{a}{2}, 0,0\right)\left(\frac{h}{q b}\right) ; & \bar{\sigma}_{x z}=\sigma_{x z}\left(0, \frac{b}{2}, 0\right)\left(\frac{h}{q b}\right) .
\end{array}
$$


Table 1. Deflection $(\bar{w})$ at the centre of a simply supported square laminate $\left(0^{\circ} / 90^{\circ} / 0^{\circ}\right)$ under uniform load of intensity $q$

\begin{tabular}{|l|l|l|l|l|l|l|}
\hline References & \multicolumn{5}{|c|}{ Thickness ratio (h/a) } \\
\hline $\begin{array}{l}\text { Present } \\
\text { Mesh: 64 elements }\end{array}$ & Theory & 0.01 & 0.02 & 0.05 & $\mathbf{0 . 1 0}$ & $\mathbf{0 . 2 5}$ \\
\cline { 2 - 7 } & HSDT & $\mathbf{0 . 6 8 9 4}$ & $\mathbf{0 . 7 1 8 5}$ & $\mathbf{0 . 8 9 5 9}$ & $\mathbf{1 . 4 6 1 1}$ & $\mathbf{3 . 8 3 1 7}$ \\
\hline Mesh: 128 elements & HSDT & $\mathbf{0 . 6 7 8 4}$ & $\mathbf{0 . 7 0 7 2}$ & $\mathbf{0 . 8 2 5 9}$ & $\mathbf{1 . 4 3 6 3}$ & $\mathbf{3 . 6 9 3 2}$ \\
\hline Mesh: 192 elements & HSDT & $\mathbf{0 . 6 7 6 4}$ & $\mathbf{0 . 7 0 5 1}$ & $\mathbf{0 . 8 2 2 8}$ & $\mathbf{1 . 4 2 0 2}$ & $\mathbf{3 . 5 1 6 4}$ \\
\hline Mesh: 256 elements & HSDT & $\mathbf{0 . 6 7 5 7}$ & $\mathbf{0 . 7 0 4 4}$ & $\mathbf{0 . 8 2 0 7}$ & $\mathbf{1 . 4 0 2 3}$ & $\mathbf{3 . 3 1 0 3}$ \\
\hline Mesh: 384 elements & HSDT & $\mathbf{0 . 6 7 5 2}$ & $\mathbf{0 . 7 0 4 0}$ & $\mathbf{0 . 8 1 6 6}$ & $\mathbf{1 . 3 5 9 4}$ & $\mathbf{3 . 0 9 2 9}$ \\
\hline Mesh: 512 elements & HSDT & $\mathbf{0 . 6 7 5 1}$ & $\mathbf{0 . 7 0 3 9}$ & $\mathbf{0 . 8 1 1 9}$ & $\mathbf{1 . 3 1 0 5}$ & $\mathbf{3 . 0 5 9 1}$ \\
\hline Mesh: 640 elements & HSDT & & & $\mathbf{0 . 8 0 6 8}$ & $\mathbf{1 . 2 5 9 5}$ & $\mathbf{3 . 0 5 3 7}$ \\
\hline Mesh: 768 elements & HSDT & & & $\mathbf{0 . 8 0 1 2}$ & $\mathbf{1 . 2 0 9 3}$ & \\
\hline Mesh: 896 elements & HSDT & & & $\mathbf{0 . 7 9 5 5}$ & $\mathbf{1 . 1 3 2 9}$ & \\
\hline Mesh: 960 elements & HSDT & & & $\mathbf{0 . 7 9 2 6}$ & 1.1146 & \\
\hline $\begin{array}{l}\text { Sheikh \& Chakrabarti }[4] \\
\text { Mesh size: } 1024 \text { elements }\end{array}$ & HSDT & 0.6708 & 0.6841 & 0.7763 & 1.0910 & 2.9093 \\
\cline { 2 - 7 } & FSDT & 0.6707 & 0.6813 & 0.7588 & 1.0235 & 2.6608 \\
\hline Reddy $[7]$ & HSDT & 0.6705 & 0.6838 & 0.7760 & 1.0900 & 2.9091 \\
\hline & FSDT & 0.6697 & 0.6807 & 0.7573 & 1.0219 & 2.6596 \\
\hline Ghosh and Dey $[12]$ & HSDT & 0.6823 & - & 0.7572 & 0.9650 & - \\
\hline
\end{tabular}

The plate is analysed with different mesh divisions and the deflection obtained at the plate centre is presented with the analytical solution of Sheikh \& Chakrabarti [4]. Reddy [7] and Ghosh and Dey [12] in Table 1. which. shows that errors with HSDT results [7] for span to thickness ratio $a / h=100$ are $0.68 \%$; at the $a / h=50$ are $2.8 \%$; at the $a / h$ $=20$ are $2 \%$; at the $a / h=10$ are $2.2 \%$ and $a / h=4$ are $4.7 \%$. It is seen that the errors are reduced at higher $a / h$, and the present results have an agreement with the analytical solutions [4], [7]. This study shows that, the size of mesh and convergent speed of method has been involved by thickness ratio $\mathrm{a} / \mathrm{h}$; it is seen that the size of mesh is needed to increase and the convergent speed is reduced at higher $h / a$.

Example 2. A comparison of maximum deflection and stresses components with other studies using FSDT with correction factor of $k=5 / 6$, HDST and third-order shear deformation theory (TSDT) for a symmetric cross-ply by different number of layers and with the same boundary conditions and the material properties as previous examples, under sinusoidal distributed load. The results are shown in Table 2.

There is a good agreement between the results obtained from other sources. To assess the improvement of HSDT over FSDT, the three-dimensional elasticity solution of Pagano [13] is also presented in these tables. In addition to the above results finite-element solution of Sheikh \& Chakrabarti [4], Reddy [2] (HDST), Rastgaar Aagaah, M. Mahinfalah, G. Nakhaie Jazar [5] (TSDT), Panda and Natarajan [6] (FSDT) and Mawenya [14] (HSDT) are included in Table $2(b / a=1)$. 
Table 2. Deflection ( $\widetilde{w})$ and stresses $\left(\bar{\sigma}_{x x}, \bar{\sigma}_{y y}, \bar{\sigma}_{x z}, \bar{\sigma}_{y z}\right.$ and $\left.\bar{\sigma}_{x y}\right)$ at the important points of a simply supported square laminate $\left(0^{\circ} / 90^{\circ} / 0^{\circ}\right)$ under sinusoidal load of amplitude $q$

\begin{tabular}{|c|c|c|c|c|c|c|c|c|}
\hline$h / a$ & References & & $\bar{w}$ & $\overline{\bar{\sigma}}_{x x}$ & $\bar{\sigma}_{y y}$ & $\bar{\sigma}_{x z}$ & $\bar{\sigma}_{y z}$ & $\bar{\sigma}_{x y}$ \\
\hline \multirow{11}{*}{0.25} & Present element & HSDT & & & & & & \\
\hline & 128 elements & & 2.3878 & 1.1783 & 0.5495 & 0.2906 & 0.3872 & 0.0757 \\
\hline & 256 elements & & 2.1417 & 1.1058 & 0,5734 & 0.2160 & 0.3020 & 0.0572 \\
\hline & 320 elements & & 1.9965 & 1.0604 & 0.5738 & 0.1988 & 0.2511 & 0.0488 \\
\hline & 384 elements & & 1.9525 & 1.0139 & 0.5657 & 0.1901 & 0.2043 & 0.0417 \\
\hline & \multirow{2}{*}{$\begin{array}{l}\text { Sheikh \& Chakrabarti [4] } \\
\text { Mesh size: } 512 \text { elements }\end{array}$} & HSDT & 1.9230 & 0.7500 & 0.5080 & 0.2023 & 0.1831 & 0.0499 \\
\hline & & $\overline{\text { FSDT }}$ & 1.7770 & 0.4430 & 0.4843 & 0.1440 & 0.1569 & 0.0371 \\
\hline & \multirow{2}{*}{ Reddy [7] } & HSDT & 1.9220 & 0.7345 & - & - & 0.1832 & - \\
\hline & & FSDT & 1.7760 & 0.4369 & - & $=$ & 0.1562 & - \\
\hline & Rastgaar Aagaah,... [5] & TSDT & 1.9700 & 0.7392 & & & 0.1884 & \\
\hline & Pagano [17] & ESL & - & 0.7550 & - & 二 & 0.2170 & - \\
\hline \multirow{13}{*}{0.1} & Present element & HSDT & & & & & & \\
\hline & 768 elements & & 0.7885 & 0.6628 & 0.3040 & 0.2453 & 0.1398 & 0.0249 \\
\hline & 832 elements & & 0.7724 & 0.6590 & 0.2998 & 0.2216 & 0.1257 & 0.0244 \\
\hline & 896 elements & & 0.7569 & 0.6552 & 0.2955 & 0.2009 & 0.1128 & 0.0241 \\
\hline & 960 elements & & 0.7420 & 0.6514 & 0.2913 & 0.1828 & 0.1012 & 0.0239 \\
\hline & Sheikh \& Chakrabarti [4] & HSDT & 0.7140 & 0.5806 & 0.2722 & 0.2437 & 0.1015 & 0.0279 \\
\hline & Mesh size: 512 elements & FSDT & 0.6700 & 0.5219 & 0.2582 & 0.1623 & 0.0918 & 0.0254 \\
\hline & Reddy $[2]$ & HSDT & 0.7130 & 0.5684 & - & - & 0.1033 & - \\
\hline & & FSDT & 0.6690 & 0.5172 & - & - & 0.0915 & - \\
\hline & Rastgaar Aagaah,.. [5] & TSDT & 0.7730 & 0.5713 & & & 0.1082 & \\
\hline & Pagano [13] & ESL & 0.7405 & 0.5900 & - & - & 0.1230 & - \\
\hline & Panda and Natarajan [6] & FSDT & 0.6274 & 0.5320 & - & - & - & 0.0250 \\
\hline & Mawenya [14] & HSDT & 0.8813 & 0.5420 & - & - & - & 0.0292 \\
\hline \multirow{12}{*}{0.01} & Present element & HSDT & & & & & & \\
\hline & Mesh: $8 \times 8$ elements & & 0.4273 & 0.5367 & 0.1788 & 0.2062 & 0.1231 & 0.0178 \\
\hline & Mesh: $12 \times 12$ elements & & 0.4333 & 0.5400 & 0.1812 & 0.2221 & 0.1068 & 0.0193 \\
\hline & Mesh: $16 \times 16$ elements & & 0.4358 & 0.5417 & 0.1820 & 0.2296 & 0.0983 & 0.0199 \\
\hline & Sheikha \& Chakrabarti [4] & HSDT & 0.4350 & 0.5496 & 0.1828 & 0.2401 & 0.0749 & 0.0215 \\
\hline & Mesh size: 512 elements & FSDT & 0.4350 & 0.5490 & 0.1825 & 0.1568 & 0.0709 & 0.0202 \\
\hline & Reddy $[2]$ & HSDT & 0.4340 & 0.5390 & $=$ & - & 0.0750 & - \\
\hline & & FSDT & 0.4340 & 0.5384 & - & - & 0.0703 & - \\
\hline & Rastgaar Aagaah,.. [5] & TSTD & 0.4630 & 0.5426 & & & 0.0463 & \\
\hline & Pagano [13] & ESL & 0.4368 & 0.5520 & - & - & 0.0938 & 0.0214 \\
\hline & Panda and Natarajan [6] & FSDT & 0.4346 & 0.5660 & - & -- & - & 0.2230 \\
\hline & Mawenya [14] & HSDT & 0.4398 & 0.5510 & - & - & - & 0.0219 \\
\hline
\end{tabular}

Example 3. A four-ply $\left(0^{0} / 90^{\circ} / 90^{\circ} / 0^{\circ}\right)$ square; $h / a=0.25$; laminate with equal thickness layers has been subjected to a uniformly distributed transverse load on top plane and the results are presented in Table 3 and Figs. 1-4. The material properties and boundary conditions are as Example 1. 
Table 3. Deflection $(\bar{w})$ and stresses $\left(\bar{\sigma}_{x x}, \bar{\sigma}_{y y}, \bar{\sigma}_{x z}, \bar{\sigma}_{y z}\right.$ and $\left.\bar{\sigma}_{x y}\right)$ at the important points of a simply supported square plate $\left(0^{\circ} / 90^{\circ} / 90^{\circ} / 0^{\circ}\right)$ under uniformly distributed transverse load of amplitude $q$.

\begin{tabular}{|c|c|c|c|c|c|c|c|c|}
\hline$h / a$ & References & & $\bar{w}$ & $\bar{\sigma}_{x x}$ & $\bar{\sigma}_{y y}$ & $\bar{\sigma}_{x z}$ & $\bar{\sigma}_{y z}$ & $\bar{\sigma}_{x y}$ \\
\hline \multirow{3}{*}{0.25} & Present element & HSDT & 1.9241 & 1.0133 & 0.7300 & 0.1824 & 0.2530 & 0.0461 \\
\hline & Pagano [13] & ESL & 1.9500 & 0.7200 & 0.6630 & 0.2190 & 0.2920 & 0.0467 \\
\hline & Rastgaar Aagaah, ... [5] & TSDT & 1.9000 & 0.6810 & 0.6470 & 0.2190 & 0.2440 & 0.0451 \\
\hline \multirow{3}{*}{0.1} & Present element & HSDT & 0.7429 & 0.6475 & 0.4269 & 0.2814 & 0.1775 & 0.0247 \\
\hline & Pagano [13] & ESL & 0.7430 & 0.5590 & 0.4010 & 0.3010 & 0.1960 & 0.0275 \\
\hline & Rastgaar Aaga & TSDT & 0.7320 & 0.5510 & 0.3940 & 0.2110 & $0 . \overline{1630}$ & 0.0451 \\
\hline \multirow{3}{*}{0.01} & & HSDT & 0.4363 & 17 & 0.2 & 0.2876 & 0.1318 & 0.0206 \\
\hline & Pagano [13] & ESL & 0.4370 & 0.5390 & 0.2760 & 0.3370 & 0.1410 & 0.0216 \\
\hline & Rastgaar Aagaah, . & TSDT & 0.4350 & 0.5390 & 0.2750 & 0.3080 & 0.1290 & 0.0216 \\
\hline
\end{tabular}

In Figs. 1 - 4, the nondimensionalized stresses at the important points are plotted. It is seen that the stresses are discontinuous and the transverse shear stresses vary parabolically along the plate thickness. The transverse shear stresses, $\bar{\sigma}_{x z}$ and $\bar{\sigma}_{y z}$, satisfy zero boundary conditions at the top and bottom surfaces of the plate.

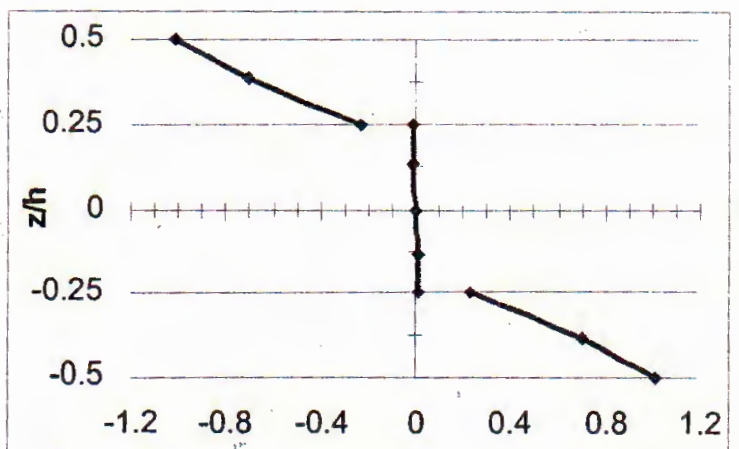

Fig. 1. Nondimensionalized normal stress $\bar{\sigma}_{x x}$ through the thickness

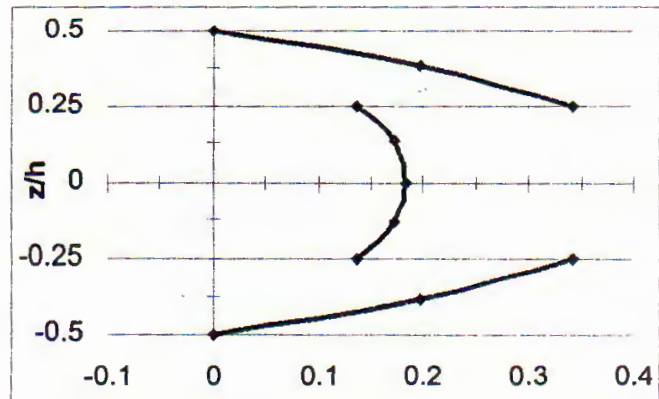

Fig. 3. Nondimensionalized normal stress $\bar{\sigma}_{x z}$ through the thickness

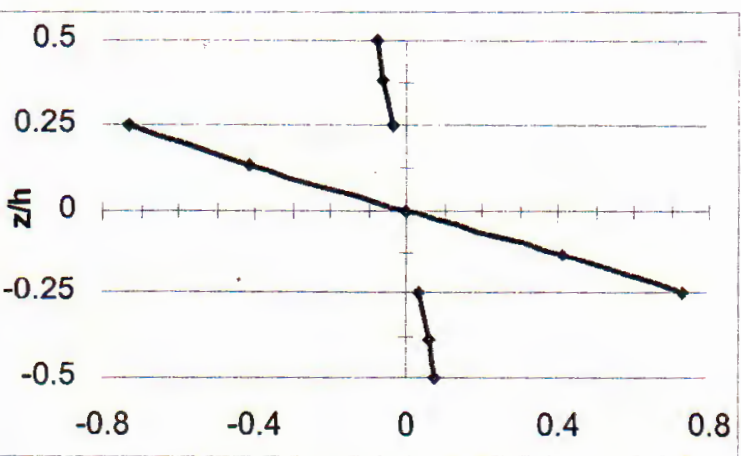

Fig. 2. Nondimensionalized normal stress $\bar{\sigma}_{y y}$ through the thickness

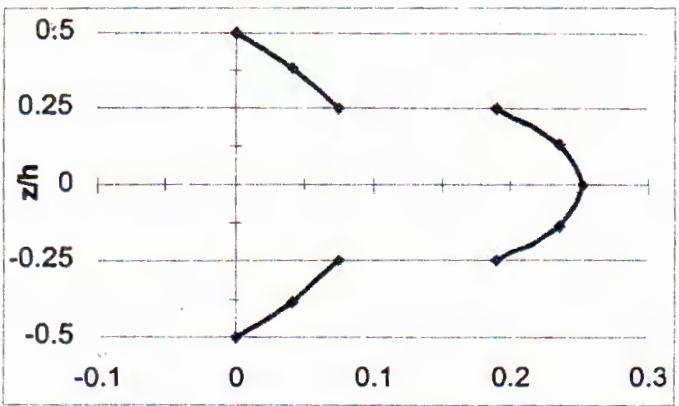

Fig. 4. Nondimensionalized normal stress $\bar{\sigma}_{y z}$ through the thickness 


\section{CONCLUSIONS}

A new rectangular element based on Reddy's simple higher-order shear deformation theory is presented. The element has four corner nodes, where each node contains $u ; v ; w ; \theta_{x}, \theta_{y}, \gamma_{x}$ and $\gamma_{y}$ as the degrees of freedom. Thus the element is quite elegant from computational point of view. The formulation is based on displacement approach where $u ; v ; w ; \gamma_{x}$ and $\gamma_{y}$ are taken as the independent displacement components. The element is tested numerically in a wide range of problems covering different boundary conditions, loading, material property, stacking sequence and so on. It shows the performance of the element in terms of accuracy, rate of convergence, applicability and so on. The element is free from shear lecking problem and it does not possess any spurious modes.

This study shows that, the size of mesh and the convergence of method have been involved by thickness ratio $h / a$. It is seen that the size of mesh is needed to increase and the convergent speed is reduced at higher $h / a$.

Based on these observations, the element can be recommended for the analysis of composite plates having any thickness to predict the deflection and stress with sufficient accuracy.

This paper is completed with financial support by the National Council for Natural Sciences.

\section{REFERENCES}

1. Tran Ich Thinh, Composite Materials: Mechanics of Materials and Structures, Ed. Education, 1994, (In Vietnamese).

2. Ngo Nhu Khoa, Modelling and Numerical Caculating for Material - Construction Composite, PhD Engineering Thersis, 2002, (In Vietnamese).

3. Tran Ich Thinh, Ngo Nhu Khoa, Higher-order finite element algorithm for the thick layered Composite plate bending problem, Proceeding of the National Conference on Engineering Mechannics, Hanoi, October 12-13, 2001.

4. A.H. Sheikh, A. Chakrabarti, A new plate bending element based on higher-order shear deformation theory for the analysis of composite plates, Int J. Elsevier Science 39 (2003) 883-903.

5. M. Rastgaar Aagaah, M. Mahinfalah, G. Nakhaie Jazar, Linear static analysis and finite element modeling for laminated composite plates using third order shear deformation theory, Int. J. Elsevier Science Composite Structures 62 (2003) 27-39.

6. S. C. Panda, R. Natarajan, Finite element analysis of laminated composite plates, Int. J. Numer. Meth. Engng 14 (1979) 69-79.

7. J. N. Reddy, A simple higher-order theory for laminated composite plates, J. Appl. Mech. (ASME) 51 (1984) 745-752.

8. R. M. Jones, Mechanics of Composite Materials, Taylor \& Francis, 1999.

9. O. O. Ochoa, Finite Element Analysis of Composite Laminates, Kluwer Academic Publishers, 1992.

10. B. N. Padya and T. Kant, Finite element analysis of laminated composite plates using a higher-order displacement model, Composites Science and Technology 32 (1988) 137-155.

11. B. N. Padya and T. Kant, Finite element stress analysis of unsymmetrically laminated composite plates based on a refined higher-order theory, Int. Conf. on Comp. Mat and Struc, New Delhi, 1988.

12. A. K. Ghosh, S. S. Dey, A simple element for the analysis of laminated plates, Comp. Struct. 44 (3) (1990) 585-596. 
13. N. J. Pagano, Exact solutions for rectangular bidirectional composites and sandwich plates, J. Compos. Mater. 4 (1970) 20-34.

14. A. S. Mawenya, J. D. Davies, Finite element bending analysis of multilayered plates, Int. J. Numer. Methods Eng. 8 (1974) 215-225.

Received December 12, 2006

\section{MÔ HİNH HOÁ PHẦ TƯ HÜ̃U HẠN TÁM COMPOSITE LỚP SƯ DỤNG LÝ THUYẾT BIẾN DANG CẮT BẬC CAO}

Nghiên cứu này tập trung vào việc phát triển phần tử tứ giác không tương thích dựa trên lý thuyết tấm biển dạng cắt bậc cao của Reddy. Mặc dù lý thuyết này được đánh giá là khá phù hợp đối với các bài toán cơ học kết cấu tấm, nhưng thực tế nó chưa được khai thác một cách hiệu quá khi áp dụng phương pháp phần tử hữu hạn trong các lời giải số. Khó khăn này ờ chỗ lý thuyết được xây dựng dụa trên giả thiểt thoá mãn đồng thời các điều kiện về tính liên tục cửa đạo hàm thành phần độ võng tại các nút chung của các phần tử và điều kiện biên về ứng suất cắt tại mặt trên và dưới của tấm. Vì vậy, mục đích được đặt ra trong bài báo này là phát triên mô hình phần tử dựa trên lý thuyết tấm của Reddy nêu trên. Phần tứ được phát triển có dạng tứ giác 4 nút, mỗi nút có 7 bậc tự do. Từ đó, thuật toán $\mathrm{PTHH}$ và chương trình mãy tính đã được xây dựng, cho phép thực hiện một lớp các bài toán. Kết quá số của chương trình đã được so sánh với một số kết quà đã công bố khác cho thấy tính chính xác và phạm vi áp dụng của phần tử đã đề xuất. 